\title{
Produção de etanol e seus impactos ambientais na indústria alcooleira de Alagoas
}

\section{Ethanol production and its environmental impacts in the alcoholic industry of Alagoas, Brazil}

\author{
Roney Calheiros de Novais ${ }^{1}$, Ivomberg Dourado Magalhães (iD) ${ }^{2}$, Cícero Luiz Calazans de Lima ${ }^{3}$, \\ Aldair Souza Medeiros (D), Giordano Bruno Medeiros Gonzaga (D)
}

${ }^{1}$ Professor, Mestre, Faculdade Pitágoras de Maceió, Maceió, Alagoas. E-mail: roneycalheiros@hotmail.com; ${ }^{2}$ Doutor em Agronomia, Produção Vegetal, PNPD, Universidade Federal de Alagoas, Rio Largo, Alagoas. E-mail: ivomberg31@hotmail.com; ${ }^{3}$ Professor, Doutor, Departamento de Fitotecnia e Fitossanidade, Universidade Federal de Alagoas, Rio Largo, Alagoas. E-mail: cicerocalazansufal@hotmail.com; ${ }^{4}$ Doutor em Agronomia, Produção Vegetal, PDJ, Universidade de São Paulo/Escola Superior de Agricultura Luiz de Queiroz, Piracicaba, São Paulo. E-mail: aldairmedeiros@gmail.com; ${ }^{5}$ Professor, Doutor, Departamento de Exatas, Centro Universitário Tiradentes, Maceió, Alagoas. E-mail: giordanogonzaga@gmail.com.

\section{A R T I G O}

Recebido: $30 / 12 / 2020$

Aprovado: 30/06/2021

Energia renovável

Cana-de-açúcar

Destilaria

Usinas
Palavras-chave:

\section{R E S U M O}

Apesar de toda tradição da agroindústria sucroenergética, é notória a preocupação da população, e principalmente, do meio científico relacionado aos impactos ambientais negativos que seus processos industriais produzem no meio ambiente. Com isto, objetivou-se com este estudo avaliar a produção de etanol, açúcar e outros derivados da cana-de-açúcar de quatro unidades industriais de Alagoas, durante três safras e pontuar os possíveis impactos ambientais provocados pelo processo de industrialização. Foi feito um levantamento com um questionário em três destilarias anexas e em uma destilaria autônoma, localizadas no estado de Alagoas. As quatro destilarias conduziram a fermentação em batelada alimentada (processo descontínuo alimentado) e possuem dorna pulmão. Duas possuem dornas abertas e duas fermentadores fechados, para recuperação do etanol arrastado pelos gases desprendidos durante a fermentação etanólica. $\mathrm{O}$ questionário foi preenchido com dados operacionais de cada destilaria. Foi avaliada a matéria prima por meio das variáveis cana - de - açúcar moída para açúcar, cana moída para álcool, \% cana moída crua, moagem horária, tipo de mosto (caldo / misto / melaço), açúcares redutores totais do mosto. Foi quantificada a produção, resíduos, eficiências e rendimentos das usinas. As destilarias avaliadas neste trabalho utilizam seus resíduos dentro de uma amplitude aceitável do ponto de vista ambiental, buscando sempre melhores tecnologias com intuito de minimizar os impactos ambientais. O procedimento operacional industrial adotado pelas quatro unidades é, salvo pequenas variações, padrão para todo o estado de Alagoas.

\section{A B S T R A C T}

Key words:

Renewable energy

Sugar cane

Distillery

Mills
Despite all the tradition of the sugarcane agro-industry, the concern and critical judgment related to the negative environmental impacts that its industrial processes can produce in the environment is notorious. The objective of this study was to evaluate the production of ethanol, sugar and other sugarcane by-products from four industrial units in Alagoas during three harvests and to assess the possible environmental impacts caused by the industrialization process. A survey was carried out with a questionnaire in three adjoining distilleries and an autonomous distillery, located in the state of Alagoas. The four distilleries led the batch fermentation fed (discontinuous fed process) and they have a fermenters lung. Two of them have opened fermenters and two closed fermenters, for the recovery of the ethanol dragged by the gases released during the ethanolic fermentation. The questionnaire was filled with operational data from each distillery. The raw material was evaluated by means of the variables sugarcane ground for sugar, cane ground for alcohol, ground cane, hourly grinding, type of must (broth / mixed / molasses), wort total reducing sugars. Production, residues, efficiencies and yields of the mills were quantified. The distilleries evaluated in this work use their residues within an acceptable range from the environmental point of view, always seeking better technologies in order to minimize environmental impacts. The industrial operating procedure adopted by the four units is, except for small variations, standard for the entire state of Alagoas.

\section{Revista Verde}

ISSN 1981-8203

Pombal, Paraíba, Brasil v. 16, n.3, jul.-set, p.298-306, 2021

doi: $10.18378 /$ rvads.v16i3.8616 


\section{INTRODUÇÃO}

A cana-de-açúcar (Saccharum spp.) possui elevada capacidade na produção de biomassa, sendo, portanto, uma das principais alternativas para diversificar a produção de energia, reduzir a dependência de combustíveis fósseis e mitigar as emissões de gases do efeito estufa (GEE) para a atmosfera (BONASSA et al., 2015). Por outro lado, apesar de toda tradição e importância do setor sucroalcooleiro na economia nacional, existem inquietações e julgamentos críticos relacionados aos impactos ambientais negativos causados pelos processos industriais desse setor (REBELATO et al., 2016). A cadeia produtiva e processamento industrial da canade-açúcar apresenta várias etapas, e, se não gerenciadas adequadamente, podem provocar impactos ambientais indesejados, principalmente, associados ao solo, água e emissões de GEE (CHRISTOFOLETTI et al., 2013).

O Brasil é líder absoluto na produção de etanol obtido a partir da cana-de-açúcar (GUEVARA et al., 2017). Porém, a indústria alcooleira utiliza a água de forma intensiva como insumo produtivo, o que gera grande quantidade de resíduos sólidos, líquidos e gasosos, advindos do setor de produção (BONASSA et al., 2015). Entre estes resíduos estão o bagaço da cana-de-açúcar, proveniente da moagem da cana para extração do caldo, que apresenta teor de umidade de aproximadamente $50 \%$, rico em polissacarídeos (açúcares complexos), como a celulose e a hemicelulose, além da lignina, mais conhecida por biomassa lignocelulósica (SILVA et al., 2014).

A busca pelo aumento da produção agrícola alinhada a preservação ambiental, está diretamente associada à necessidade do desenvolvimento de indicadores de desempenho ambiental, que possam avaliar os atuais impactos ambientais das operações industriais, assim como indicar a evolução da atuação ambiental da empresa a partir de intervenções com vistas à melhoria do desempenho (ROHRICH; CUNHA, 2004).

Neste contexto, apesar da literatura apresentar vários estudos sobre os resíduos poluentes da indústria sucroenergética e seus impactos ambientais (NOGUEIRA; GARCIA, 2013; REBELATO et al., 2013, 2016), observa-se que pesquisas avaliando a relação entre a produção de etanol e os impactos causados no meio ambiente na região Nordeste do Brasil, especificamente, no estado de Alagoas, ainda são incipientes. Esse tipo de estudo é extremamente necessário em regiões produtoras de cana-de-açúcar, como é o caso do estado alagoano, para quantificar os impactos ambientais promovidos por esse setor, e, a partir dos resultados obtidos traçar mecanismos para o desenvolvimento sustentável no setor alcooleiro. Desse modo, objetivou-se com este estudo avaliar a produção de etanol e os impactos ambientais provocados pelos resíduos das indústrias sucroenergéticas no estado de Alagoas.

\section{MATERIAL E MÉTODOS}

Para a avaliação dos impactos ambientais gerados pela produção de etanol no estado de Alagoas, foram coletadas informações em quatro usinas, nas safras 2014/2015, 2015/2016 e 2016/2017, sendo três anexas (destilarias que estão acopladas a uma usina para produção de açúcar) e uma autônoma (unidade industrial que só produz etanol), esta última só forneceu dados para as safras 2014/15 e 2015/16.

O levantamento foi realizado por meio de questionário distribuído nas referidas unidades industriais e de consultas informais aos responsáveis pelas respostas do questionário, além de outras questões de caráter geral. Para preservar a identidade destas indústrias, as mesmas estão denominadas de usinas/destilarias A, B, C e D.

Ressalte-se que as unidades industriais amostradas conduziram a fermentação etanólica em batelada alimentada (processo descontínuo alimentado). As unidades B e C operam com dornas fechadas e recuperação do etanol arrastado pelos gases produzidos durante a fermentação, por meio de lavagem dos mesmos com água em coluna específica.

A avaliação das informações foi realizada quantificandose os diversos derivados, oriundos da produção de etanol, assim como, a destinação dos mesmos. As principais variáveis avaliadas foram: água usada na lavagem de cana-de-açúcar, preparação de mosto, limpeza de equipamentos e piso; bagaço de cana-de-açúcar (NOGUEIRA; GARCIA, 2013); vinhaça produzida no processo de destilação para a produção de etanol (WANG et al., 2006); cinzas resultantes da queima do bagaço nas caldeiras; produção de óleo fúsel (NOGUEIRA; GARCIA, 2013).

No questionário, foram solicitadas informações como moagem de cana, produção de açúcar, produção de etanol hidratado, produção de etanol anidro, de torta filtro rotativo, álcool etílico de $2^{\mathrm{a}}$, óleo de fúsel, $\mathrm{kg}$ de açúcar por tonelada de cana, $\mathrm{kg}$ de melaço por tonelada de cana e litros de etanol por tonelada de cana, consumo de ácido sulfúrico e de ciclohexano; água utilizada na lavagem da cana e na lavagem dos gases liberados durante a fementação, entre outras, para que se possa ter uma visão global de uma unidade sucroalcooleira.

Foram calculados os principais resíduos da cana (bagaço, vinhaça e $\mathrm{CO}_{2}$ liberado na fermentação do mosto) para cada safra. Para estes cálculos foi considerada a quantidade de bagaço (média estimada para Alagoas) presente em uma tonelada de cana e a quantidade de vinhaça (média estimada para Alagoas) obtida para cada litro de etanol produzido, em todas as unidades produtivas (VASCONCELOS, 1983).

\section{RESULTADOS E DISCUSSÃO}

As usinas A, B e C possuem destilarias anexas, enquanto a destilaria D é autônoma (só produz etanol). Logo, nas destilarias autônomas, toda moagem de cana-de-açúcar é direcionada para a produção de etanol. Por outro lado, nas usinas com destilaria anexa, a cana moída e distribuída para a produção de açúcar e de etanol. Nas destilarias anexas, a produção de etanol ocorre utilizando-se melaço e caldo (mosto misto). O melaço é proveniente da fabricação de açúcar, resíduo obtido de aproximadamente 30 litros ou $40 \mathrm{~kg}$ por tonelada de cana processada (VASCONCELOS, 1983). A cana moída para açúcar nas três usinas com destilarias anexas foi maior que para etanol, pelo fato de trabalharem com mosto misto, utilizando-se melaço e caldo para a produção de etanol. A crise que se abateu sobre a agroindústria da cana-de-açúcar vitimou a destilaria autônoma $\mathrm{D}$, que não moeu cana na safra 2016/17.

Na Tabela 1, estão representados os valores de produção de cana-de-açúcar das três usinas com destilarias anexas (A, B e C) e da destilaria autônoma (D), durante três safras (2016/2017, 2015/2016 e 2014/2015). Para a safra de 2016/2017 a usina C moeu para produção de açúcar 1.514.066,423 toneladas de cana. Este valor é $44 \%$ e $48 \%$ superior em relação às usinas $\mathrm{A} \mathrm{e} \mathrm{B}$, respectivamente. 
Tabela 1. Cana-de-açúcar processada de três usinas no estado de Alagoas (A, B e C) e da destilaria autônoma (D) durante três safras $(2016 / 2017,2015 / 2016$ e 2014/2015).

\begin{tabular}{|c|c|c|c|c|c|c|}
\hline \multirow[b]{3}{*}{ Usina/Destilaria } & \multicolumn{6}{|c|}{ Cana-de-açúcar } \\
\hline & \multicolumn{6}{|c|}{ Safra $2016 / 2017$} \\
\hline & CMA & CMAL & $\mathrm{MH}$ & $\mathrm{CC}$ & TP & ARTM \\
\hline & \multicolumn{3}{|c|}{-------------------------ton--------------- } & $\%$ & $\%$ & \\
\hline A & $657.587,48$ & $13.494,27$ & 261,64 & 22,8 & Caldo/mel & 14,29 \\
\hline $\mathrm{B}$ & $720.564,55$ & $4.171,66$ & 261,51 & - & Caldo/mel & 16,91 \\
\hline $\mathrm{C}$ & $1.514 .066,42$ & $138.808,92$ & 496,98 & 61,61 & Caldo/mel & 14,54 \\
\hline D (N. moeu) & - & - & - & - & - & - \\
\hline \multicolumn{7}{|c|}{ Safra $2015 / 2016$} \\
\hline A & $628.391,66$ & $9.220,416$ & 269,21 & 26,17 & Caldo/mel & 15,01 \\
\hline $\mathrm{B}$ & $955.624,58$ & $54.898,98$ & 292,30 & - & Caldo/mel & 18,32 \\
\hline $\mathrm{C}$ & $1.661 .510,52$ & $230.315,02$ & 143,31 & 78,38 & Caldo/mel & 14,85 \\
\hline $\mathrm{D}$ & 0 & $200.171,50$ & 143,31 & - & CALDO & 14,85 \\
\hline \multicolumn{7}{|c|}{ Safra $2014 / 2015$} \\
\hline A & $976.309,59$ & $81.133,32$ & 281,70 & 23,84 & Caldo/mel & 14,91 \\
\hline $\mathrm{B}$ & $1.275 .808,17$ & 172,534 & 323,40 & - & Caldo/mel & 18,13 \\
\hline $\mathrm{C}$ & $2.031 .785,68$ & $49.662,00$ & 466,65 & 70,77 & Caldo/mel & 15,05 \\
\hline $\mathrm{D}$ & 0 & $290.655,10$ & 156,91 & - & CALDO & 14,64 \\
\hline
\end{tabular}

CMA- Cana moída para açúcar; CMAL- Cana moída para álcool; MH- Moagem horária; CC- Cana crua; TP- Tipo de mosto; ARTM- Açúcar total recuperado do mosto.

Na safra 2015/2016 a usina C moeu para a produção de açúcar 1.661.510,520 toneladas de cana. Este valor é superior em 38 e 58\% em relação às usinas $\mathrm{A}$ e $\mathrm{B}$, respectivamente. Já na safra 2014/2015, novamente a usina $C$ obteve destaque para esta variável $(2.031 .785,68 \mathrm{t})$, superando em 48 e $63 \%$ em relação às usinas $\mathrm{A}$ e $\mathrm{B}$, respectivamente. De acordo Lima (2001), uma tonelada de cana-de-açúcar moída produz em média 850 litros de caldo, onde 78 a $86 \%$ é água, 10 a 20\% é sacarose e o restante, são outros compostos. A alta produção de sacarose comprova a aptidão desta cultura para produção de açúcar e etanol, pois enquanto as plantas em geral convertem menos de $1 \%$ da luz solar em energia química, a cana-deaçúcar é capaz de converter cerca de $2 \%$ da radiação incidente em açúcares, dos quais dois terços estão na forma de lignina e de celulose.

A quantidade de cana-de-açúcar moída destinada para produção de etanol foi menor em relação à produção de açúcar em todas as usinas com destilarias anexas nas safras avaliadas. A usina C obteve a maior produção $(230.315,020$ t) de canade-açúcar para produção de etanol na safra 2015/2016. Em média, na usina $\mathrm{C}$ foram destinadas para produção de etanol $139.595,313$ t cana-de-açúcar nas três safras avaliadas, enquanto as usinas A e B moeram em média 34.616,020 e $19.747,720 \mathrm{t}$ de cana para produção de etanol, respectivamente. A destilaria D moeu 290.655,100 e 200.171,500 t de cana-deaçúcar para produção de etanol nas safras 2014/2015 e 2015/2016, respectivamente. Essa destilaria não moeu na safra 2016/2017.

No Brasil, a produção de cana-de-açúcar na safra 2015/2016 foi 5\% maior em relação à safra 2014/2015 e 2,2\% maior em relação à safra 2016/2017, gerando 33,84 milhões de toneladas de açúcar, 18,57 bilhões de litros de etanol hidratado e 11,66 bilhões de litros de anidro, que é destinado à mistura na gasolina. Nesta mesma safra, o estado de Alagoas produziu 16,382 milhões de toneladas de cana, 1,2 milhão de toneladas de açúcar, 163 milhões de litros de etanol hidratado e 215 milhões de litros de etanol anidro (MAPA, 2016). Porém a CONAB (2017) afirma que na safra 2014/2015, no Brasil,
46,9\% da cana foi destinada para a produção de açúcar e $53,1 \%$, para a produção de etanol.

Valores semelhantes foram verificados para as usinas A e $B$ na moagem de cana nas duas primeiras safras analisadas (2016/2017: 261,64 e 261,51 t ha-1;2015/2016: 269,21 e $292,30 \mathrm{t} \mathrm{ha}^{-1}$ ) para a produção de açúcar e etanol. A usina C, na safra 2016/2017, moeu 496,98 t ha-1, alcançando uma diferença de $53 \%$ das demais usinas anexas avaliadas nesta pesquisa. A destilaria D moeu em média $150,11 \mathrm{tha}^{-1}$ nas safras 2014/2015 e 2015/2016.

A usina A, nas três safras utilizou em média $24,3 \%$ de cana crua, enquanto a usina $C$ utilizou em média 44,12\%. Já usina $\mathrm{B}$ e a destilaria $\mathrm{D}$, não utilizaram cana crua em nenhuma safra avaliada. Conforme Arévalo (1998), a colheita da cana crua apresenta algumas vantagens, como por exemplo, maior flexibilidade da colheita; aumento das atividades microbianas e melhoria da estrutura do solo; menor custo dos tratos culturais; proteção do solo contra erosão e radiação. Portanto, a moagem de cana-de-açúcar crua (sem a tradicional queima da palhada antes do corte), para a fabricação de açúcar e etanol, é uma tendência crescente e irreversível, haja vista que há legislação específica (11241/02) proibindo, de forma programada, a moagem de cana-de-açúcar queimada.

As três destilarias anexas utilizaram o mesmo tipo de mosto (caldo mais mel). A destilaria D utilizou apenas mosto de caldo. $\mathrm{O}$ açúcar total recuperado do mosto (ARTM) foi em média 14,$7 ; 17,8 ; 14,8$ e 14,7\% para as usinas A, B, C e D, respectivamente.

A produção do açúcar Very High Polarization (VHP) é o tipo mais exportado pelo Brasil. No seu branqueamento não há a utilização de anidrido sulfuroso. Para este açúcar especial, a usina $\mathrm{C}$ obteve destaque, alcançando nas três safras em média 1.825.848 sacos (Tabela 2). O açúcar VHP tem entre 99,1 e $99,69 \%$ de polarização e cor. Quanto mais baixo esse índice, mais claro ou mais branco é o açúcar (ZACURA FILHO; PICCIRILLI, 2012). Para a produção de açúcar cristal as usinas A e a B produziram 117.358 e 2.603 sacos na safra 2016/2017, porém, não produziram mais este açúcar nas demais safras. A 
usina $\mathrm{C}$ foi quem mais produziu açúcar cristal nas três safras avaliadas, com produção média de 1.345 .208 sacos.

A produção de etanol hidratado na usina $\mathrm{C}$ obteve maior destaque, com média de $18.250 \mathrm{~m}^{3}$ nas três safras avaliadas, seguida pela destilaria D, com média nas safras 2014/2015 e 2015/2016 de $17.686 \mathrm{~m}^{3}$ e Usina B $\left(16.356 \mathrm{~m}^{3}\right)$. A Usina A obteve a menor média $\left(5.087 \mathrm{~m}^{3}\right)$ de álcool hidratado, nas três safras. De acordo com a CONAB (2017), a capacidade nominal diária do estado de Alagoas para a produção de etanol hidratado é de 3.344.000 L dia ${ }^{-1}$. Para a Produção de etanol
Anidro, a usina $\mathrm{C}$ apresentou maiores valores para as safras 2016/2017 e 2014/2015, sendo em média de $26.437 \mathrm{~m}^{3}$. Na safra $2016 / 2017$ a usina B produziu $3.270 \mathrm{~m}^{3}$ a mais que a usina A, porém na safra 2014/2015 a Usina A chegou a produzir $6.328 \mathrm{~m}^{3}$ a mais que a usina $\mathrm{B}$. O total de etanol produzido (hidratado mais anidro) são enviados para armazenagem em tanques de grande volume, situados em parques de tanques, onde aguardam a comercialização e posterior remoção por caminhões (CONAB, 2017).

Tabela 2. Produção de diversos produtos da cana-de-açúcar de três usinas (A, B e C) e uma destilaria autônoma (D) no estado de Alagoas durante três safras (2016/2017, 2015/2016 e 2014/2015).

\begin{tabular}{|c|c|c|c|c|}
\hline \multirow{3}{*}{ PRODUÇÃO } & \multicolumn{2}{|c|}{ Usina/Destilaria } & \multirow[b]{2}{*}{$\mathrm{C}$} & \multirow[b]{2}{*}{$\mathrm{D}$} \\
\hline & A & $\mathrm{B}$ & & \\
\hline & \multicolumn{3}{|c|}{----------------- Safra 2016/2017---------- } & \\
\hline Produção de açúcar VHP (sacos) & 1.087 .419 & 1.414 .959 & 1.624 .428 & Não moeu \\
\hline Produção de açúcar cristal (sacos) & 117.358 & 2.603 & 1.409 .050 & \\
\hline Produção de etanol hidratado $\left(\mathrm{m}^{3}\right)$ & 4,397 & 18,854 & 11,744 & \\
\hline Produção de etanol anidro $\left(\mathrm{m}^{3}\right)$ & 10,208 & 13,478 & 28,846 & \\
\hline Produção média diária de açúcar $(\mathrm{kg})$ & 9,127 & 10,739 & 11,000 & \\
\hline Produção média diária de etanol hidratado $\left(\mathrm{m}^{3}\right)$ & 33 & 70 & 120 & \\
\hline Produção média diária de etanol anidro $\left(\mathrm{m}^{3}\right)$ & 77 & 130 & 280 & \\
\hline Destino do etanol de $2^{\mathrm{a}}$ & Redestilar & - & Redestilar & \\
\hline Açúcares redutores no vinho & 0,701 & 0,453 & 0,42 & \\
\hline \multirow[t]{2}{*}{ Teor alcoólico do vinho (GL) } & 6,2 & 7,48 & 8,39 & \\
\hline & \multicolumn{2}{|c|}{ Safra $2015 / 2016$} & & \\
\hline Produção de açúcar VHP (sacos) & 967.005 & 1.610 .163 & 1.443 .965 & \\
\hline Produção de açúcar cristal (sacos) & - & - & 1.220 .261 & \\
\hline Produção de etanol hidratado $\left(\mathrm{m}^{3}\right)$ & 2,055 & 17,527 & 31,825 & 13.666 \\
\hline Produção de etanol anidro $\left(\mathrm{m}^{3}\right)$ & 9,485 & 4,821 & 19,837 & - \\
\hline Produção média diária de açúcar $(\mathrm{kg})$ & 6,762 & 9,148 & 22,000 & - \\
\hline Produção média diária de etanol hidratado $\left(\mathrm{m}^{3}\right)$ & 14,37 & 99,59 & 120 & 130,2 \\
\hline Produção média diária de etanol anidro $\left(\mathrm{m}^{3}\right)$ & 66,33 & 130 & 280 & - \\
\hline Destino do etanol de $2^{\mathrm{a}}$ & Redestilar & - & Redestilar & - \\
\hline Açúcares redutores no vinho & 0,562 & 0,49 & 0,49 & - \\
\hline \multirow[t]{2}{*}{ Teor alcoólico do vinho (GL) } & 6,57 & 7,97 & 7,50 & 5,94 \\
\hline & \multicolumn{2}{|c|}{ Safra 2014/2015 } & & \\
\hline Produção de açúcar VHP (sacos) & 1.708 .322 & 2.211 .259 & 2.409 .152 & \\
\hline Produção de açúcar cristal (sacos) & - & - & 1.406 .313 & \\
\hline Produção de etanol hidratado $\left(\mathrm{m}^{3}\right)$ & 8,809 & 29,654 & 11,179 & 21.705 \\
\hline Produção de etanol anidro $\left(\mathrm{m}^{3}\right)$ & 14,155 & 7,826 & 30,625 & - \\
\hline Produção média diária de açúcar $(\mathrm{kg})$ & 8,584 & 9,656 & 11,000 & - \\
\hline Produção média diária de etanol hidratado $\left(\mathrm{m}^{3}\right)$ & 44,27 & 129,5 & 120 & 147,7 \\
\hline Produção média diária de etanol anidro $\left(\mathrm{m}^{3}\right)$ & 71,13 & 130 & 280 & - \\
\hline Destino do etanol de $2^{\mathrm{a}}$ & Redestilar & - & Redestilar & - \\
\hline Açúcares redutores no vinho & 0,602 & 0,48 & 0,49 & - \\
\hline Teor alcoólico do vinho $\left({ }^{\circ} \mathrm{GL}\right)$ & 6,89 & 8,9 & 7,21 & 6,28 \\
\hline
\end{tabular}

O etanol hidratado é mais conhecido como o etanol comum vendido nos postos de combustíveis, enquanto o etanol anidro é aquele misturado à gasolina. A principal diferença entre os dois está relacionado à quantidade de água presente em cada um deles. O etanol hidratado é um combustível que possui em sua composição entre 95,1 e $96 \%$ de etanol e o restante de água, enquanto o etanol anidro possui pelo menos $99,6 \%$ de graduação alcoólica.

Dessa forma, o etanol anidro é praticamente etanol puro. $\mathrm{O}$ etanol anidro é misturado à gasolina para baratear o combustível, aumentar sua octanagem e reduzir a emissão de poluentes, o que se tornou uma preocupação mundial nos últimos anos (ZACURA FILHO; PICCIRILLI, 2012). Essa é uma das ações voltadas para a mitigação das emissões antrópicas de GEE. A Lei N8.723, de 1993, estipulou a mistura de etanol anidro na gasolina. Em poucos anos, novos decretos alteraram a porcentagem da mistura. Desde 16 de março de 2015, o percentual obrigatório de etanol anidro combustível na gasolina comum é de $27 \%$.

O estado de Alagoas apresentou uma produção relevante no ano 2009, com valor de 790,9 milhões de litros. Entretanto, nas safras 2014/2015, 2015/2016 e 2016/2017, essa produção caiu para 555, 378 e 383 milhões de litros, respectivamente. Os dados obtidos denotam que o estado de Alagoas produz mais etanol anidro que etanol hidratado e consome menos da metade de sua produção total. 
A produção média diária de açúcar VHP, cristal, ou a soma dos dois, em cada unidade é muito semelhante nas três safras analisadas. Para a usina A, a média é de 8.158 sacos (de $50 \mathrm{~kg}$ ), na usina B foi de 9.848 sacos e, na usina C, 22.000 sacos, sendo a maior produtora. Obedecendo à mesma tendência da produção diária de açúcar, a produção média diária de etanol hidratado e a produção média diária de etanol anidro, a destilaria $\mathrm{C}$ apresentou melhor desempenho, chegando a 120 e $280 \mathrm{~m}^{3}$ de etanol hidratado e etanol anidro, respectivamente. A usina $\mathrm{D}$ apresentou média diária de $139 \mathrm{~m}^{3}$ de etanol hidratado nas duas safras avaliadas. O destino do etanol de $2^{\mathrm{a}}$, em todas as destilarias avaliadas, é a redestilação, misturando-o, por meio da dorna volante, ao vinho (mosto fermentado).

A usina "A" apresentou maior quantidade de açúcares redutores no vinho (média de $0,62 \%$ ), quando comparado com as demais usinas B $(0,47 \%)$ e C $(0,45 \%)$, nas três safras avaliadas para a produção de açúcar e etanol. Para Santos et al. (2017), açúcares redutores são carboidratos que possuem grupo carbonílico livre, capaz de se oxidar na presença de agentes oxidantes em solução alcalina. Os autores ainda afirmam que a glicose e frutose são os principais açucares redutores utilizados na fermentação. Della-Bianca et al. (2013) ratificam que esses carboidratos são dois dos principais monossacarídeos presentes em processos fermentativos, dentre os quais se destacam a produção de vinho, cachaça e etanol combustível.

Para o teor de etanol do vinho, pela equação de Gay Lussac $\left({ }^{\circ} \mathrm{GL}\right)$, a usina $\mathrm{C}$ apresentou maior teor $\left(8,39^{\circ} \mathrm{GL}\right) \mathrm{em}$ relação à usina $\mathrm{B}\left(7,5^{\circ} \mathrm{GL}\right)$ e usina $\mathrm{A}\left(6,2^{\circ} \mathrm{GL}\right)$ na safra 2016/2017. Na safra 2015/2016 a usina B apresentou maior teor $\left(7,97^{\circ} \mathrm{GL}\right)$ que a usina $\mathrm{C}\left(7,50^{\circ} \mathrm{GL}\right)$ e maior que a usina A $\left(6,57^{\circ} \mathrm{GL}\right)$. Na safra $2014 / 2015$, a usina B apresentou teor de $8,9^{\circ} \mathrm{GL}$, usina $\mathrm{C}$ obteve $7,21^{\circ} \mathrm{GL}$ e a usina A $6,89^{\circ} \mathrm{GL}$, enquanto a usina $\mathrm{D}$ apresentou média de $6,11^{\circ} \mathrm{GL}$ de teor de etanol no vinho nas duas safras avaliadas (2014/2015 e 2015/2016).

No Brasil, a produção de etanol é feita exclusivamente por via fermentativa. Conforme Bonassa et al. (2015), a vinhaça, vinhoto ou restilo, é o líquido derivado da destilação do vinho, que é resultante da fermentação do caldo da cana de açúcar ou melaço. $\mathrm{O}$ volume varia basicamente entre 10 a 15 $\mathrm{L} / \mathrm{L}$ de etanol, dependendo do teor de etanol do vinho e o vapor direto.

Como um dos principais resíduos da cana-de-açúcar, o melaço foi produzido em maior quantidade pela usina $\mathrm{A}$, com $72,31 \mathrm{~kg}$ por tonelada de cana processada. As usinas B e C praticamente não obtiveram diferenças significativas, 62,36 e $61,65 \mathrm{~kg} \mathrm{ton}^{-1}$, respectivamente, para a safra 2016/2017 (Tabela 3). Resultado semelhante foi verificado na safra 2014/2015, obedecendo à mesma tendência, com a usina A $\left(60,36 \mathrm{~kg} \mathrm{ton}^{-1}\right)$ se destacando, com o resultado mais elevado, seguida de perto pela usina $\mathrm{B}\left(54,89 \mathrm{~kg} \mathrm{ton}^{-1}\right)$ e usina $\mathrm{C}(53,57$ $\mathrm{kg}$ ton $^{-1}$ ). A usina $\mathrm{D}$ não produziu esta variável para nenhuma safra avaliada neste estudo, porque não produz açúcar. Para Bonassa et al. (2015), o melaço é o principal subproduto da indústria do açúcar, sendo produzido na proporção de 40 a 60 $\mathrm{kg}$ ton $^{-1}$ de cana processada, justificando os resultados encontrados nas usinas avaliadas nesta pesquisa.

Em todas as destilarias anexas avaliadas, o destino do melaço foi a própria destilaria, com o objetivo de fabricação de etanol. Isto é justificado, de acordo com Nogueira et al. (2013), devido ao elevado teor de açúcares totais e demais componentes, deixando claro a vantagem das unidades mistas com a possibilidade de aproveitamento do melaço residual que, após passar por processo de reidratação, é destinado à fabricação de álcool etílico. Esse uso adiciona valor ao subproduto, que normalmente é destinado à alimentação animal, cujo preço de comércio representa apenas uma fração do preço do produto principal, o açúcar.

O bagaço da cana-de-açúcar é outro importante derivado. Para esta variável, na safra 2016/2017, a usina B produziu 327 $\mathrm{kg}$ ton $^{-1}$ de cana processada, enquanto a usina A produziu 315 $\mathrm{kg}$ ton $^{-1}$. A usina C produziu $301 \mathrm{~kg} \mathrm{ton}^{-1}$ e a destilaria D não moeu nesta safra. Na safra 2014/2015, as usinas A e B produziram praticamente a mesma quantidade de bagaço de cana $\left(314,6\right.$ e $314,0 \mathrm{~kg}$ ton $^{-1}$ de cana, respectivamente), seguidas pela usina $\mathrm{C}$, com $303 \mathrm{~kg}^{-1}$ ton $^{-1}$ de cana e a usina $\mathrm{D}$, com $308 \mathrm{~kg} \mathrm{ton}^{-1}$ de cana. Estes resultados são superiores aos encontrados por Cortez et al. (1992), no qual para 1 tonelada de cana moída, produz-se aproximadamente $250 \mathrm{~kg}$ de bagaço. Porém, de acordo com a CONAB (2011), a produção do bagaço depende do tipo de cana-de-açúcar utilizada, das condições climáticas, do solo etc, sendo que as variedades comumente utilizadas no Brasil produzem entre 270 e $290 \mathrm{~kg}$ por tonelada de cana processada.

Ressalte-se que estas quantidades de bagaço são obtidas após o processo de extração (em moendas ou difusores), onde ocorre adição de água ao material triturado (operação denominada embebição). Todas as usinas avaliadas destinaram o bagaço da cana-de-açúcar para as caldeiras, com o objetivo de gerar vapor. Cortez et al. (1992), estudando os principais derivados da agroindústria canavieira e sua valorização, concluíram que a energia embutida no bagaço, é maior do que a contida no etanol produzido, pois $250 \mathrm{~kg}$ de bagaço podem gerar, quando convertido em energia calórica, $560.000 \mathrm{kcal}$. A queima do bagaço em caldeiras fornece um rendimento térmico em torno de $85 \%$. Porém, com esta queima, são produzidos alguns poluentes como cinzas, fuligens, monóxido (CO) e dióxido de carbono $\left(\mathrm{CO}_{2}\right)$ e óxido nitroso $\left(\mathrm{N}_{2} \mathrm{O}\right)$. Um ponto positivo na utilização desta técnica, é que grande parte das usinas tornam-se autossuficientes energeticamente e em alguns casos, possibilita a venda do excedente, processo denominado de cogeração (PIACENTE, 2005).

As usinas A, B e C, nas três safras avaliadas (2016/2017, 2015/2016 e 2014/2015) e a D, nas duas safras (2015/2016 e 2014/2015) conseguiram manter a umidade do bagaço variando de 49 a 51\%. Estes resultados corroboram com Santos et al. (2011) que encontrarem 50\% com o bagaço recémmoído. Os referidos autores ainda explicam que a estocagem do bagaço nos pátios das usinas é um dos fatores que contribuem para a ineficiência de sua exploração. Zacura Filho e Piccirilli (2012) afirma que sua simples deposição ao ar livre, favorece a fermentação natural, apodrecimento e diminuição de seu rendimento energético. O poder calorífico do bagaço torna-se maior à medida que o teor de umidade se reduz, principalmente devido à menor necessidade de calor para vaporizar a água (GUEVARA et al., 2017). Ainda, Almeida et al. (2008) afirma que a disposição física das pilhas é difícil devido seus volumes. Em grande parte das usinas brasileiras, um trator espalha o bagaço no alto da pilha, que pode chegar a ter cerca de $300 \mathrm{~m}$ de extensão, $100 \mathrm{~m}$ de largura e $40 \mathrm{~m}$ de altura. 
Tabela 3. Produção e destino de derivados da cana-de-açúcar de três usinas (A, B e C) e uma destilaria autônoma (D), no estado de Alagoas, durante três safras (2016/2017, 206/2015 e 2014/2015).

\begin{tabular}{|c|c|c|c|c|}
\hline \multirow[b]{2}{*}{ RESÍDUOS } & \multicolumn{2}{|c|}{ Usina/Destilaria } & \multirow[b]{2}{*}{$\mathrm{C}$} & \multirow[b]{2}{*}{$\mathrm{D}$} \\
\hline & A & B & & \\
\hline & \multicolumn{3}{|c|}{--------------- Safra 2016/2017------------ } & \\
\hline Melaço por tonelada de cana (kg) & 72,31 & 62,36 & 61,65 & N. moeu \\
\hline Destino do melaço & Venda/álcool & Venda/álcool & Venda/álcool & \\
\hline Bagaço por tonelada de cana (kg) & 315 & 327 & 301 & \\
\hline Destino do bagaço & Caldeiras & Caldeiras & Caldeiras & \\
\hline Umidade do bagaço & 50,25 & 49,22 & 49,09 & \\
\hline Pol do bagaço & 2,68 & 3,30 & 2,08 & \\
\hline ART do bagaço & - & 3.47 & - & \\
\hline Torta por tonelada de cana $(\mathrm{kg})$ & 33.71 & 32 & 38 & \\
\hline Destino da torta & Campo & Campo & Campo & \\
\hline Pol da torta & 3,35 & 2,69 & 1,62 & \\
\hline Vinhaça por litro de etanol (L) & 14 & 14 & 13 & \\
\hline Destino da vinhaça & Irrigação & Irrigação & Irrigação & \\
\hline Teor alcoólico da vinhaça (GL) & - & 0.03 & 0.01 & \\
\hline Temperatura da vinhaça $\left({ }^{\circ} \mathrm{C}\right)$ & - & 100 & 60 & \\
\hline Água de lavagem por tonelada de cana $\left(\mathrm{m}^{3}\right)$ & 5,74 & 5 & 2 & \\
\hline Destino da água de lavagem de cana & Irrigação & Irrigação & Irrigação & \\
\hline Cinzas das caldeiras por tonelada de cana $(\mathrm{kg})$ & - & 5.49 & - & \\
\hline \multicolumn{5}{|l|}{ Safra $2015 / 2016$} \\
\hline Melaço por tonelada de cana $(\mathrm{kg})$ & 62,65 & 53,37 & 60,99 & N. produz \\
\hline Destino do melaço & Venda/álcool & Venda/álcool & Venda/álcool & N. produz \\
\hline Bagaço por tonelada de cana $(\mathrm{kg})$ & 310 & 320,48 & 308,91 & 308 \\
\hline Destino do bagaço & Caldeiras & Caldeiras & Caldeiras & Caldeiras \\
\hline Umidade do bagaço & 51,47 & 49,92 & 50,55 & 51,60 \\
\hline Pol do bagaço & 2,64 & 2,26 & 2,02 & 2,46 \\
\hline ART do bagaço & - & 2,37 & - & - \\
\hline Torta por tonelada de cana $(\mathrm{Kg})$ & 30,45 & 31,24 & 38,17 & N. produz \\
\hline Destino da torta & Campo & Campo & Campo & N. produz \\
\hline Pol da torta & 3,12 & 2,92 & 2,74 & N. produz \\
\hline Vinhaça por litro de etanol (L) & 14 & 14,00 & 13 & 14 \\
\hline Destino da vinhaça & Irrigação & Irrigação & Irrigação & Irrigação \\
\hline Teor alcoólico da vinhaça (GL) & - & 0,0329 & 0,0380 & 0,006 \\
\hline Temperatura da vinhaça $\left({ }^{\circ} \mathrm{C}\right)$ & - & 100 & 60 & - \\
\hline Água de lavagem por tonelada de cana $\left(\mathrm{m}^{3}\right)$ & 5,58 & 5,00 & 2.000 & - \\
\hline Destino da água de lavagem de cana & Irrigação & Irrigação & Irrigação & Tratamento \\
\hline Cinzas das caldeiras por tonelada de cana $(\mathrm{kg})$ & - & 0,50 & - & - \\
\hline \multicolumn{5}{|l|}{ Safra 2014/2015 } \\
\hline Melaço por tonelada de cana $(\mathrm{kg})$ & 60,36 & 54,89 & 53,57 & N. produz \\
\hline Destino do melaço & Venda/álcool & Venda/álcool & Venda/álcool & N. produz \\
\hline Bagaço por tonelada de cana $(\mathrm{kg})$ & 314,6 & 314 & 303 & 308 \\
\hline Destino do bagaço & Caldeiras & Caldeiras & Caldeiras & Caldeira \\
\hline Umidade do bagaço & 49,84 & 50,08 & 50,13 & 49,81 \\
\hline Pol do bagaço & 2,81 & 2,11 & 1,95 & 2,24 \\
\hline ART do bagaço & - & 2,22 & 4,52 & - \\
\hline Torta por tonelada de cana $(\mathrm{kg})$ & 29,91 & 28,3 & 45,54 & N. produz \\
\hline Destino da torta & Campo & Campo & Campo & N. produz \\
\hline Pol da torta & 3,68 & 2,69 & 2,33 & N. produz \\
\hline Vinhaça por litro de etanol (L) & 14 & 14 & 13 & 14 \\
\hline Destino da vinhaça & Irrigação & Irrigação & Irrigação & Irrigação \\
\hline Teor alcoólico da vinhaça (GL) & - & 0,02 & 0,02 & \\
\hline Temperatura da vinhaça $\left({ }^{\circ} \mathrm{C}\right)$ & - & 100 & 60 & - \\
\hline Água de lavagem por tonelada de cana $\left(\mathrm{m}^{3}\right)$ & 5,32 & 5 & 2 & - \\
\hline Destino da água de lavagem de cana & Irrigação & Irrigação & Irrigação & Tratamento \\
\hline Cinzas das caldeiras por tonelada de cana $(\mathrm{kg})$ & - & 7,04 & - & - \\
\hline
\end{tabular}

Pol do Bagaço nada mais é que o teor de sacarose, aferido por polarímetro ou sacarímetro. Nesta variável, a usina B obteve maior valor $(3,30 \%)$, seguido da usina $\mathrm{A}(2,68 \%)$ e a usina $\mathrm{C}$ obteve a melhor performance $(2,08 \%)$ para a safra 2016/2017. Nas duas últimas safras avaliadas (2014/2015 e 2015/2016) a destilaria A obteve a pior performance, com valor 
(média de 2,72\%). A destilaria D obteve o segundo pior resultado (média de 2,35\%) para o teor de sacarose. A usina B obteve o segundo melhor resultado médio de $2,18 \%$ e o melhor resultado foi o da usina $\mathrm{C}$ (média de 1,98\%). Estes valores corroboram os encontrados por Santos et al. (2011), indicando que, quando a umidade do bagaço se encontra com 49 e $50 \%$, a pol do bagaço geralmente varia de 2 a 3\%, respectivamente. Zacura Filho e Piccirilli (2012) afirmam que para cada ponto de pol que se baixa no bagaço no processo de extração de caldo, obtém-se um rendimento em torno de três quilos de açúcar.

Para os açúcares redutores totais (ART) do bagaço, a única usina que quantificou esta variável para as safras 2016/2017, 2015/2016, 2014/2015 foi a B (média de 2,69\%). A usina C, na safra 2014/2015, determinou o ART do bagaço, encontrando o valor $(4,52 \%)$. Os valores da usina B estão dentro dos estipulados por Della-Bianca et al. (2013), avaliando o desempenho do pré-tratamento com peróxido de hidrogênio alcalino para a hidrólise enzimática de bagaço de cana-de-açúcar, encontrando valores entre 3,5 e 4,2\%.

A usina $\mathrm{C}$ obteve uma maior quantidade de torta de filtro, $38 \mathrm{~kg}$ por tonelada de cana processada, enquanto as usinas A e $\mathrm{B}$ produziram 34 e $32 \mathrm{~kg}$ ton $^{-1}$, respectivamente, na safra 2016/2017. Para a safra 2015/2016, as usinas A, B e C produziram 30,$5 ; 31,3$ e $38,5 \mathrm{~kg}^{-1}$ ton $^{-1}$ cana, respectivamente. Na safra 2014/2015 a usina C ampliou ainda mais esta variável, produzindo $45,5 \mathrm{~kg} \mathrm{ton}^{-1}$ de cana, enquanto as usinas A e B diminuíram suas produções de torta de filtro para 30 e $28,3 \mathrm{~kg}$ ton $^{-1}$ de cana processada, respectivamente. Porém estes valores estão dentro da amplitude estipulada por Bonassa et al. (2015), onde citam que para cada tonelada de cana processada produzse de 20 a $45 \mathrm{~kg}$ de torta. Para Rebelato et al. (2013) torta de filtro é o resíduo da filtração mecânica durante a fabricação do açúcar e do etanol, originada da mistura do lodo de decantação e do bagacilho, este proveniente da peneiração do bagaço e a mistura de ambos enviada ao filtro contínuo rotativo à vácuo, onde se obtém o resíduo denominado torta de filtro. A destilaria $\mathrm{D}$ não produz torta de filtro por ser uma unidade autônoma.

O destino da torta produzida a partir da cana processada, para as usinas A, B e C, foi ao campo, aplicada como adubo. De acordo com Bonassa et al. (2015), esse resíduo é rico em minerais (nitrogênio, fósforo, potássio, cálcio, magnésio e enxofre) e matéria orgânica, principalmente, proteínas e lipídeos, podendo ser utilizado para alimentação animal ou ainda como adubo.

Para a pol da torta, a usina A obteve maiores valores nas três safras, respectivamente, $3,35,3,12$ e 3,68\%, o que indica que houve uma pior performance do sistema de filtração da mistura lodo e bagacilho. A usina B obteve média de 2,77\% para as três safras e a usina C obteve média de $2,56 \%$ para estas safras. Os valores encontrados nesta pesquisa para o pol da torta são superiores aos desejados para esta variável, que são abaixo de 1,0\% (REBELATO et al., 2013). Ainda segundo este autor, os valores de pol da torta de filtro estão diretamente relacionados com a velocidade de operação das máquinas, pois velocidade superior a 10 rotações por hora (rph) ocasiona perdas. O ideal é operar com rotação baixa, para uma melhor eficiência do filtro.

Para a produção da vinhaça, as usinas A, B e C geraram quantidades similares nas três safras estudadas 14, 14 e 13 litros de vinhaça por L de álcool etílico, respectivamente. A destilaria D produziu $14 \mathrm{~L}$ de vinhaça por L de etanol nas safras 2014/2015 e 2015/2016. A vinhaça é um resíduo de processo de destilação do etanol. Para cada L de etanol produzido, são gerados de 10 a $14 \mathrm{~L}$ de vinhaça, o que ratifica os resultados aferidos nas usinas estudadas (CHRISTOFOLETTI et al., 2013).

Toda vinhaça gerada nas destilarias avaliadas é destinada para as lavouras, na forma de irrigação (fertirrigação). Em 2014, foram gerados no Brasil cerca de 280 bilhões de litros de vinhaça e $97 \%$ desse volume foram usados na própria lavoura. Silva et al. (2014) relatam que quando a vinhaça é aplicada no solo, o mesmo é alterado, gerando modificações em parte de suas propriedades químicas, uma vez que altera o $\mathrm{pH}$ e os teores de potássio trocáveis. Para Silva et al. (2007) estas alterações no solo favorecem o aumento da disponibilidade de alguns nutrientes para as plantas. É uma importante alternativa econômica, já que as indústrias sucroalcooleiras gastam menos com adubos (SILVA et al., 2014). Entretanto, esse subproduto pode contaminar corpos d'água (WANG et al., 2006) e, quando em excesso, causa diversos tipos de impactos ambientais (CHRISTOFOLETTI et al., 2013).

A usina A não aferiu o teor de etanol da vinhaça em nenhuma safra avaliada, enquanto a usina B apresentou 0,03 e $0,02{ }^{\circ} \mathrm{GL}$ de teor de etanol, nas safras 2016/2017 e 2014/2015, respectivamente. A usina $\mathrm{C}$ mediu 0,01 e $0,02{ }^{\circ} \mathrm{GL}$ para as mesmas safras. Os resultados desta pesquisa estão dentro do aceitável e, de acordo com a Wang et al. (2006), esta certifica que a graduação alcoólica da vinhaça não pode ser superior a $0,03^{\circ} \mathrm{GL}$.

A temperatura da vinhaça variou para duas destilarias. A destilaria B $\left(100^{\circ} \mathrm{C}\right)$ e a $\mathrm{C}\left(60^{\circ} \mathrm{C}\right)$ para as safras $2016 / 2017$ e 2014/2015. Essa variação ocorreu devido a coleta da amostra antes do trocador de calor $\mathrm{K}$ na usina $\mathrm{B}$, que resfria a vinhaça, enquanto na usina $\mathrm{C}$, a amostra foi coletada após o trocador de calor k. Para Silva et al. (2014), a temperatura ideal da vinhaça que sai dos aparelhos de destilação é de 85 a $90^{\circ} \mathrm{C}$. Porém, Wang et al. (2006) reportam que a diminuição da temperatura da vinhaça para abaixo de $60^{\circ} \mathrm{C}$, ideal $45^{\circ} \mathrm{C}$, permite o uso de materiais com menor custo como tanques e tubulações de fibra e o uso de geomembranas sintéticas de impermeabilização, que não toleram a elevada temperatura da vinhaça que sai da destilaria (cerca de $100^{\circ} \mathrm{C}$ caso não haja reaproveitamento regenerativo do seu calor).

A lavagem da cana de açúcar é a etapa de maior demanda de água em todo o processo. A usina $\mathrm{A}$ foi a que mais utilizou água para esta etapa, 5,74 e 5,32 $\mathrm{m}^{3}$ ton $^{-1}$ de cana, para as safras 2016/2017 e 2014/2015, respectivamente. As usinas B e C utilizaram a mesma quantidade de água, 5 e $2 \mathrm{~m}^{3}$ ton $^{-1}$ de cana paras as duas safras avaliadas. De acordo com Christofoletti et al. (2013) a taxa de aplicação de água para lavagem de cana pode variar de 2 a $7 \mathrm{~m}^{3}$ ton $^{-1}$ de cana, correspondendo em aproximadamente $25 \%$ do volume total de água utilizado no processo. Portanto, a operação de reciclagem da água de lavagem de cana tem sido amplamente empregada, visando à redução no consumo e, principalmente, visando à questão dos impactos ambientais com a diminuição deste recurso.

Todas as usinas avaliadas utilizam a água de lavagem de cana em circuito fechado, porém, ao fazerem o descarte, destinam a água de lavagem para irrigação. O lodo da lavagem de cana tem contribuído para que retornem nutrientes ao campo, auxiliando a lavoura quando incorporados ao solo (LIMA, 2001).

As cinzas são oriundas da queima do bagaço nas caldeiras. Para esta variável, apenas a usina B apresentou resultados, em média de $4,34 \mathrm{~kg}$ ton $^{-1}$ de cana para as três safras 
estudadas. De acordo com Bonassa et al. (2015), uma tonelada de cana pode gerar $16,5 \mathrm{~kg}$ de cinzas. As cinzas de caldeira de bagaço de cana-de-açúcar, por apresentarem quantidades consideráveis de nutrientes de plantas, podem ser aproveitadas em solos de baixa fertilidade natural, melhorando as suas características físico-químicas (SILVA et al., 2014).

\section{CONCLUSÃO}

A agroindústria da cana-de-açúcar em Alagoas, em particular a do etanol, traz vantagens do ponto de vista ambiental, por ser atividade cuja matéria-prima é renovável.

A vinhaça, produzida em grande quantidade, é aplicada em sua totalidade nos canaviais, não gerando problemas ambientais.

As destilarias em Alagoas utilizam seus resíduos dentro de uma amplitude aceitável do ponto de vista ambiental, buscando sempre melhores tecnologias com intuito de minimizar os impactos ambientais.

\section{REFERÊNCIAS}

ALMEIDA, A. C. S.; SOUZA, J. L.; TEODORO, I; BARBOSA, G. V. S.; MOURA- FILHO, G. M; FERREIRA JÚNIOR, R. A. Desenvolvimento vegetativo e produção de variedades de cana-de-açúcar em relação à disponibilidade hídrica e unidades térmicas. Ciência e Agrotecnologia, v.32, n.5, p.1441-1448, 2008. 10.1590/S1413-70542008000500013.

ARÉVALO, R. A. Plantas daninhas nos resíduos de colheita de cana crua e seu controle. Stab, v.16, n.4, p. 24-5, 1998.

BONASSA, G.; SCHNEIDER, L. T.; FRIGO, K. D. A.; FEIDEN, A.; TELEKEN, J. G.; FRIGO, E. P. Subprodutos gerados na produção de bioetanol: bagaço, torta de filtro, água de lavagem e palhagem. Revista Brasileira de Energias Renováveis, v.4, p.144-166, 2015. 10.5380/rber.v4i3.44075.

CHRISTOFOLETTI, C. A.; PEDRO-ESCHER, J; CORREIA, J. E.; MARINHO, J. F. U.; FONTANETTI, C. S. Sugarcane vinasse: Environmental implications of its use. Waste Management, v.33, p.2752- 2761, 2013. $\underline{10.1016 / \text { j.wasman.2013.09.005. }}$.

CONAB. Companhia Nacional de Abastecimento. A geração termoelétrica com a queima do bagaço de cana-de-açúcar no Brasil - Análise do Desempenho da Safra 2009-2010. 2011. Disponível em: https://www.gov.br/agricultura/ptbr/assuntos/sustentabilidade/agroenergia/arquivos-

termoeletrica-com-a-queima-do-bagaco-de-cana-deacucar/termoeletrica-com-a-queima-do-bagaco-de-cana-deacucar-no-brasil-safra-2009-2010.pdf. Acessado em: $26 / 08 / 2020$

CONAB. Companhia Nacional de Abastecimento. Acompanhamento de safra brasileira: grãos. Sétimo levantamento, abril, 2017. Brasília: CONAB, 2017. v.4 SAFRA 2016/17- n.7. Disponível em: www.conab.gov.br/boletim_graos_abril_2017.pdf. Acessado em: 26/08/2020
CORTEZ, L.; MAGALHÃES, P.; HAPPI, J. Principais subprodutos da agroindústria canavieira e sua valorização. Revista Brasileira de Energia, v.2, n.2, p.1-17, 1992.

DELLA-BIANCA, B. E.; BASSO, T. O.; STAMBUK, B. U.; BASSO, L. C.; GOMBERT, A. K. What do we know about the yeast strains from the Brazilian fuel ethanol industry? Applied Microbiology and Biotechnology, v.97, n.3, p.979-991, 2013. 10.1007/s00253-012-4631-X.

GUEVARA, A. J. H.; SILVA, O. R.; HASEGAWA, H. L.; VENANZI, D. Avaliação de sustentabilidade da produção de etanol no Brasil: Um modelo em dinâmica de sistemas. Brazilian Business Review, v.14, n.4, p.435-447, 2017. 10.15728/bbr.2017.14.4.5.

LIMA, U. A. Processos fermentativos e enzimáticos. In: LIMA, U. A.; AQUARONE, E.; BORZANI, W.; SCHMIDELL, W. (eds.) Biotecnologia industrial. São Paulo: Edgard Blücher, 2001. v.3, p.1-43.

MAPA. Ministério da Agricultura, Pecuária e Abastecimento. Relação das unidades produtoras cadastradas no departamento da cana-de-açúcar e agroenergia. Brasília: MAPA. 2016. Disponível em: www.gov.br/agricultura/ptbr/assuntos/sustentabilidade/agroenergia/acompanhamentoda-producao-sucroalcooleira/resumos/cadastro.pdf. Acessado em:

NOGUEIRA, M. A. F. S.; GARCIA, M. S. Gestão dos resíduos do setor industrial sucroenergético: estudo de caso de uma usina no município de Rio Brilhante, Mato Grosso do Sul. Electronic Journal of Management, Education and Environmental Technology, v.17, n.17, p.3275-3283, 2013. $10.5902 / 2236117010444$.

PIACENTE, F. J. Agroindústria canavieira e o sistema de gestão ambiental: o caso das usinas localizadas nas bacias hidrográficas dos rios Piracicaba, Capivari e Jundiaí. 2005. 175 f. Dissertação (Mestrado em Desenvolvimento Econômico) Universidade Estadual de Campinas, Campinas - SP, 2005.

REBELATO, M. G.; MADALENO, L. L.; RODRIGUES, A. M. Análise do desempenho ambiental das usinas sucroenergéticas localizadas na bacia hidrográfica do rio Mogi Guaçu. Engenharia Sanitária e Ambiental, v.21, n.3, p.579591, 2016. 10.1590/S1413-41522016126712.

REBELATO, M. G.; MADALENO, L. L.; RODRIGUES, A. M. Ponderação do impacto ambiental dos resíduos e subprodutos da produção industrial sucroenergética. Revista Gestão Industrial, v.9, n.2, p.392-415, 2013. 10.3895/S1808$\underline{04482013000200006 .}$.

ROHRICH, S. S.; CUNHA, J. C. A proposição de uma taxonomia para a análise da gestão ambiental no Brasil. Revista de Administração Contemporânea, v.8, n.4, p.81-97, 2004. $10.1590 / \mathrm{S} 1415-65552004000400005$.

SANTOS, A. A.; DEOTI, J. R.; MÜLLER, G.; DÁRIO, M. G.; STAMBUK, B. U.; ALVES JUNIOR, S. L. Microwell platebased method for the determination of reducing sugars with the 
DNS reagent. Brazilian Journal of Food Technology, v.20, e2015113, 2017. 10.1590/1981-6723.11315.

SANTOS, M. L.; LIMA, O. J.; NASSAR, E. J.; CIUFFI, K. J.; CALEFI, P. Estudo das condições de estocagem do bagaço de cana-de-açúcar por análise térmica. Química Nova, v.34, n.3, p.507-511, 2011. 10.1590/S0100-40422011000300024.

SILVA, A. P, M.; BONO, J. A. M.; PEREIRA, F. A. R. Aplicação de vinhaça na cultura da cana-de-açúcar: Efeito no solo e na produtividade de colmos. Revista Brasileira de Engenharia Agrícola e Ambiental, v.18, n.1, p.38-43, 2014. $\underline{10.1590 / \text { S1415-43662014000100006. }}$.

SILVA, M. A. S.; GRIEBELER, N. P.; BORGES, L. C. Uso de vinhaça e impactos nas propriedades do solo e lençol freático. Revista Brasileira de Engenharia Agrícola e Ambiental, v.11, n.1, p.108-114, 2007. 10.1590/S141543662007000100014.

VASCONCELOS, J. N. Estudo sobre a composição química da vinhaça de diferentes procedências no estado de Alagoas. Saccharum Apc, v.6, n.29, p.40-48, 1983.

WANG, Y.-D.; Mo, Y.-C.; WANG, W. H.; LI, Y.-R.; YE, Y.$P$. Effect of vinasse irrigation on the activity of three enzymes and agronomic characters at seedling stage of sugarcane. Sugar Tech, v.8, p.264-267, 2006. 10.1007/BF02943566.

ZACURA FILHO, G.; PICCIRILLI, J. P. Açúcar e Álcool: Desde a lavoura da cana até o produto acabado. 1. ed. Santa Cruz do Rio Pardo - SP: Editora Viena, 2012. 93p. 